\title{
Cushing's storm secondary to a rare case of ectopic ACTH secreting metastatic breast cancer
}

\author{
Maura Bucciarelli' ${ }^{2}$, Ya-Yu Lee' and Vasudev Magaji' \\ ${ }^{1}$ Division of Endocrinology, and ${ }^{2}$ Department of Medicine, Lehigh Valley Health Network, Allentown, \\ Pennsylvania 18103, USA
}

Correspondence

should be addressed

to V Magaji

Email

vasudevgmagaji@gmail.com

\section{Summary}

Ectopic ACTH secretion from breast cancer is extremely rare. We report a case of a 30-year-old woman with a history of breast cancer, who presented with psychosis and paranoid behaviour. CT of the head showed white matter disease consistent with posterior reversible encephalopathy syndrome (PRES). Despite using mifepristone with multiple antihypertensives including lisinopril, spironolactone and metoprolol, she was hypertensive. Transaminitis did not allow mifepristone dose escalation and ketoconazole utilization. Etomidate infusion at a non-sedating dose in the intensive care unit controlled her hypertension and cortisol levels. She was transitioned to metyrapone and spironolactone. She was discharged from the hospital on metyrapone with spironolactone and underwent chemotherapy. She died 9 months later after she rapidly redeveloped Cushing's syndrome and had progressive metastatic breast cancer involving multiple bones, liver and lungs causing respiratory failure.

\section{Learning points:}

- Cushing's syndrome from ectopic ACTH secreting breast cancer is extremely rare.

- Cushing's syndrome causing psychosis could be multifactorial including hypercortisolism and PRES.

- Etomidate at non-sedating doses in intensive care setting can be effective to reduce cortisol production followed by transition to oral metyrapone.

\section{Background}

Ectopic adrenocorticotrophic hormone (ACTH) production causing Cushing's syndrome is most often associated with small cell carcinoma of the lung, but less common aetiologies include non-small cell lung carcinoma, carcinoids, pancreatic tumours, medullary thyroid carcinoma and pheochromocytoma (1). Breast cancer is a very rare cause of ectopic ACTH syndrome (2) (3). Psychiatric manifestations from ectopic ACTH syndrome are seen in about half the cases (1). Our patient is a rare case of posterior reversible encephalopathy syndrome (PRES) with ectopic ACTH-associated Cushing's syndrome from breast cancer. Etomidate infusion, which inhibits $11-\beta$-hydroxylase, at non-sedating doses in a monitored setting and oral metyrapone subsequently was successful for the reduction of hypercortisolism. Spironolactone was used to block the mineralocorticoid action of excessive cortisol and deoxycortisol resulting from etomidate inhibition of cortisol synthesis. This was a novel and unique strategy to successfully control the blood pressure and reduce cortisol levels needed for PRES management resulting in the patient's psychosis resolution.

\section{Case presentation}

A 31-year-old female with triple negative, high grade invasive right breast ductal carcinoma treated with chemotherapy, bilateral mastectomy and radiation presented with acute psychosis. She had T2N1M0 infiltrating ductal breast carcinoma treated neoadjuvantly with 
four cycles of doxorubicin and cyclophosphamide followed by four cycles of paclitaxel followed by bilateral mastectomies and radiation therapy. On presentation she had not slept for 4 days and was hyperenergetic, easily distracted, impulsive with racing thoughts and pressured speech and paranoid that her husband was trying to hurt her. On exam she had a round, ruddy, hirsuite face with acne and her blood pressure was 156/108.

\section{Investigation}

Laboratory studies showed potassium $1.7 \mathrm{mEq} / \mathrm{l}$ (normal range $3.7-5.2 \mathrm{mEq} / \mathrm{l})$, random cortisol $>70 \mathrm{mcg} / \mathrm{dl}$ (normal range $6-23 \mathrm{mcg} / \mathrm{dl}$ ) and $1 \mathrm{and} 8 \mathrm{mg}$ overnight dexamethasone tests showed cortisol $>100 \mathrm{mcg} / \mathrm{dl}$ (normal range $<1.8 \mathrm{mcg} / \mathrm{dl}$ ). She had elevations in AST to $103 \mathrm{IU} / 1$ (normal range 10-34 IU/1), ALT $237 \mathrm{IU} / 1$ (normal range $8-37 \mathrm{IU} / \mathrm{l}$ ), ACTH $1173 \mathrm{pg} / \mathrm{ml}$ (normal range $9-52 \mathrm{pg} / \mathrm{ml}$ ), total testosterone $170 \mathrm{ng} / \mathrm{dl}$ (normal range $15-70 \mathrm{ng} / \mathrm{dl}$ in women), DHEA-S $499 \mathrm{mcg} / \mathrm{dl}$ (normal range $45-270 \mathrm{mcg} / \mathrm{dl}$ ), $17 \mathrm{OH}$ progesterone $1780 \mathrm{ng} / \mathrm{dl}$ (normal range $<200 \mathrm{ng} / \mathrm{dl}$ ) and 24-h urine cortisol (UFC) $14766 \mathrm{mcg} /$ day (normal range $10-100 \mathrm{mcg} /$ $24 \mathrm{~h}$ ). A computed tomography (CT) of the abdomen showed extensive hepatic metastatic disease and bilateral adrenal hyperplasia. Renin, aldosterone, plasma metanephrines, chromagranin A, corticotropin-releasing hormone and gastrin levels were normal. Imaging was negative for thyroid nodule, thymic neoplasm and bronchial carcinoid. Core liver biopsy revealed metastatic breast adenocarcinoma that was negative for neuroendocrine markers CD56, synaptophysin, neuron specific enolase, chromogranin and ACTH. A CT of the head showed white matter disease consistent with PRES (Fig. 1).

\section{Treatment}

She was hypertensive and psychotic despite using mifepristone with multiple antihypertensives including lisinopril, aldactone and metoprolol, targeting a systolic blood pressure of 110-130. Transaminitis did not allow mifepristone dose increase above $600 \mathrm{mg} /$ day and utilization of ketoconazole. Etomidate infusion at $0.1 \mathrm{mg} / \mathrm{kg}$ per min in intensive care unit (ICU) controlled her hypertension and cortisol levels to $20-30 \mathrm{mcg} / \mathrm{dl}$. UFC decreased to $820 \mathrm{mcg} /$ day. She was transitioned to metyrapone $1250 \mathrm{mg}$ per mouth (p.o.) every $6 \mathrm{~h}$ and spironolactone $100 \mathrm{mg}$ p.o. every $6 \mathrm{~h}$. Repeat CT scans showed resolution of white matter disease following blood pressure control (Fig. 2).

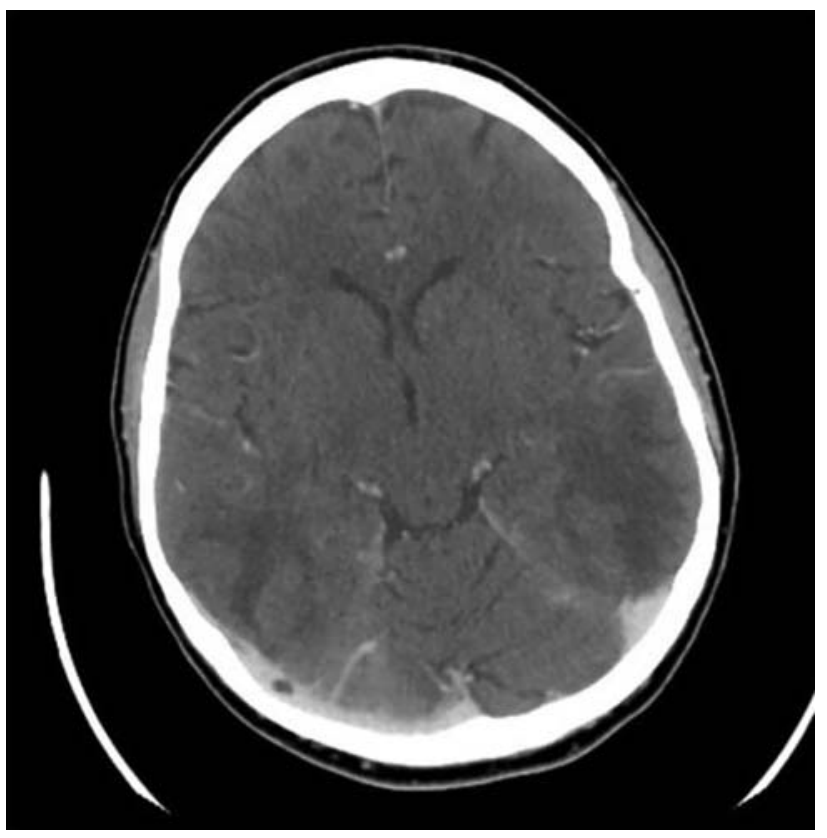

Figure 1

$\mathrm{CT}$ head with contrast showing diffuse areas of abnormal low attenuation mostly involving the subcortical white matter of the medial frontal and parietal lobes as well as the subcortical and deep white matter of the occipital and posterior temporal lobes consistent with PRES.

\section{Outcome and follow-up}

Post-hospitalization, monthly random cortisol ranged between 7.5 and $15.5 \mathrm{mcg} / \mathrm{dl}$ for 8 months. Since the patient's re-biopsy was 10\% ER positive, the patient was started on tamoxifen and completed nine cycles of gemcitabine/carboplatin. Her lower cortisol levels allowed de-escalation of the metyrapone dose to $500 \mathrm{mg}$ p.o. every $6 \mathrm{~h}$ and provided useful biochemical evidence of chemotherapeutic success of her breast cancer management. There was improvement in her liver metastases on repeat CT scans. Her metastatic bone lesions were treated with denosumab. She died after 9 months from the time of her initial presentation with ectopic ACTH Cushing's syndrome despite chemotherapy after developing new progressive metastatic lung, bone and liver lesions associated with worsening liver functions, Cushing's recurrence and rapid respiratory failure.

\section{Discussion}

Paraneoplastic syndromes could have varied presentation including, for example, endocrine hypercalcemia, syndrome of inappropriate anti diuretic hormone (SIADH), peripheral neuropathy, Eaton-Lambert syndrome and dermatomyositis-polymyositis. Mild hypercortisolism in 


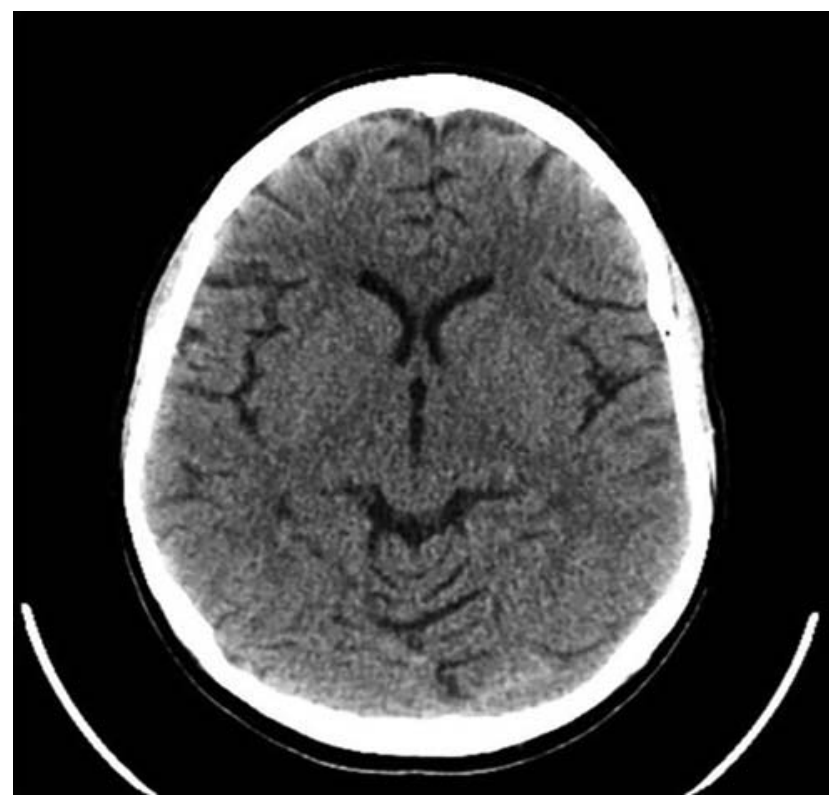

Figure 2

Resolution of PRES change noted on CT scan.

malignancy characterized by loss of circadian rhythm is associated with poor prognosis and can be mediated through interleukin-6 and interleukin-10 independent of ACTH levels (2). Cushing's syndrome resulting usually from ectopic ACTH secretion and rarely from ectopic CRH has been described in literature (3). Cushing's syndrome presentation is associated with a huge underlying tumour burden, inadequate chemotherapy response and increased susceptibility to infections from immunosuppression and has very diverse clinical manifestations characterized by symptoms of proximal muscle weakness, acne, altered mental status, hyperpigmentation, hirsuitism, hypertension along with biochemical alteration of hyperglycemia, hypokalemia, alkalosis, high testosterone and DHEA-S levels (4).

The patient's work up was negative for more likely causes including neuroendocrine tumour, medullary thyroid cancer, pituitary and adrenal tumours, thymic masses and pheochromocytoma. Among the very few cases of breast cancer causing ectopic Cushing's syndrome-described ACTH staining, mRNA demonstration by real-time PCR and in situ hybridization technique have been used (3) (5). In breast cancer, neuroendocrine differentiated carcinoma with ectopic ACTH secretion and breast carcinoma with neuroendocrine differentiation has been described (6). The lack of ACTH staining of the tumour in our case could be explained by the possibility that the subpopulation of ACTH-producing cells may have not be biopsied (7). However, the

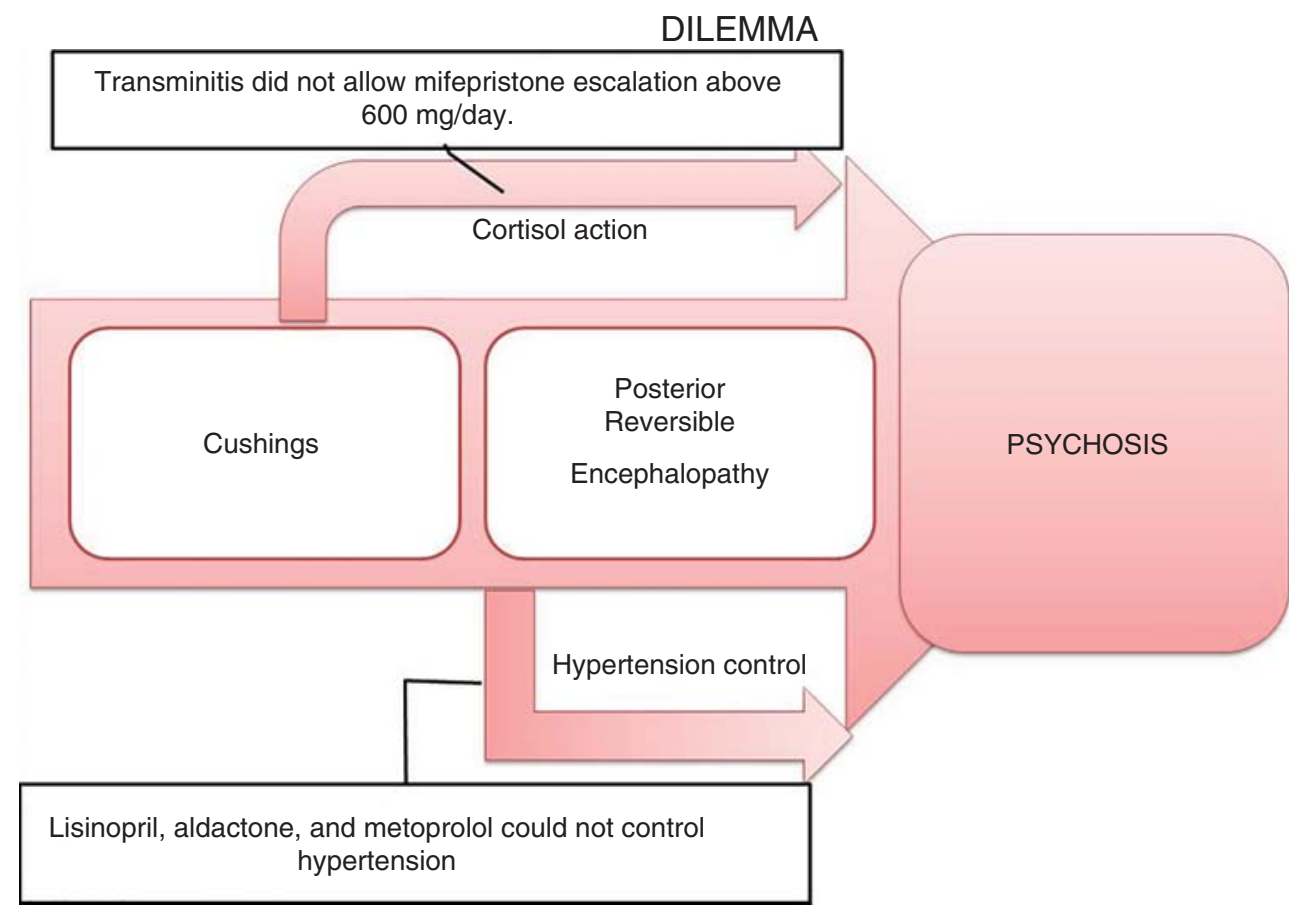

Figure 3

Dilemma in managing the patient's psychosis and PRES. 


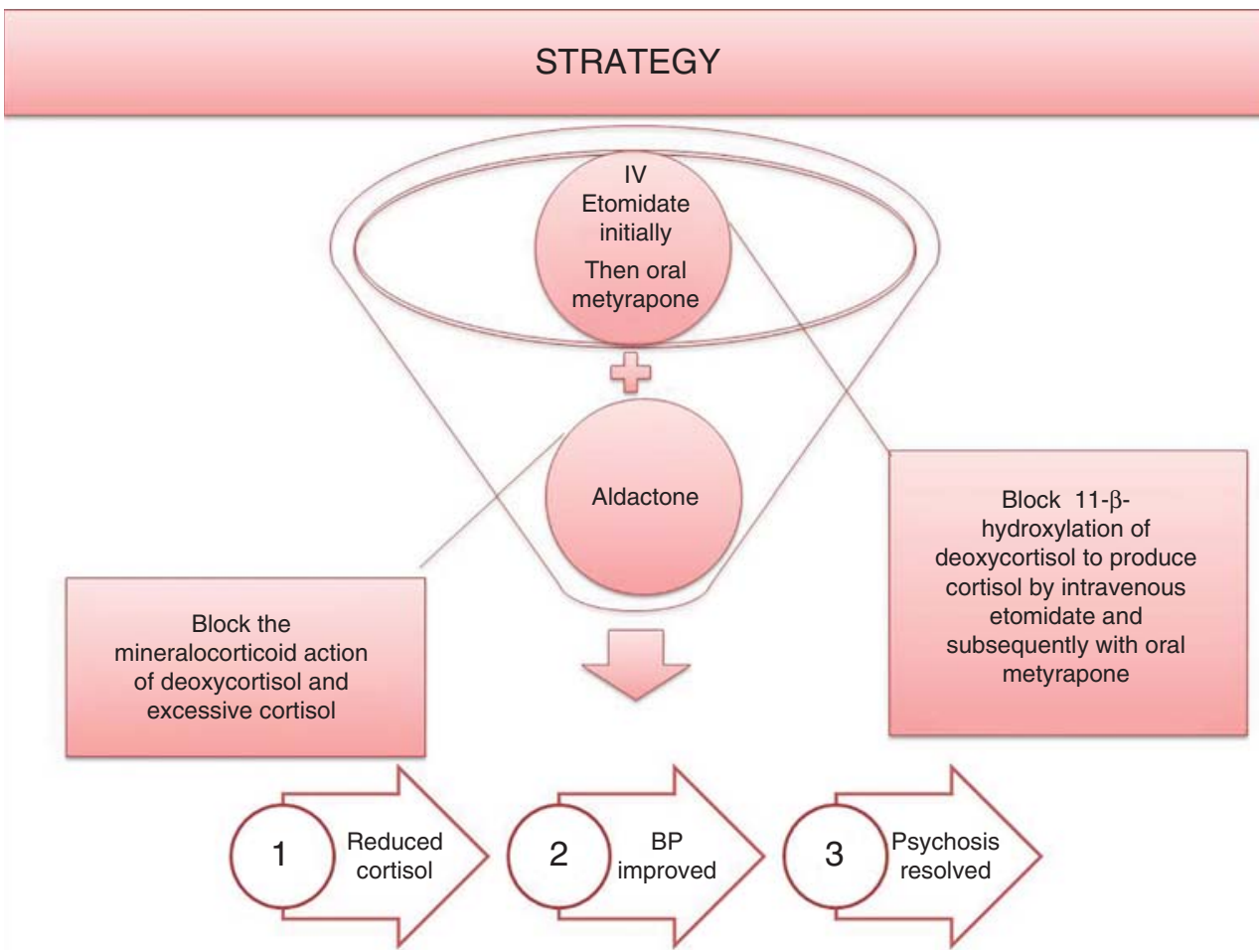

\section{Figure 4}

Strategy to manage patient's psychosis and PRES.

biochemical response of cortisol reduction following initiation of chemotherapy for breast cancer supports the diagnosis of breast cancer associated ectopic ACTH secretion in our patient.
Equally important to the assessment of ectopic Cushing's aetiology was the patient's psychosis that needed emergent management. The acute psychosis evaluation with imaging revealed changes consistent

Table 1 Outlining the hormones in time in correlation with chemotherapy.

\begin{tabular}{|c|c|c|c|c|c|c|}
\hline Day & $\begin{array}{c}\text { Chemotherapy cycle } \\
\text { initiation day }\end{array}$ & $\begin{array}{l}\text { Cortisol } \\
\text { (mcg/dl) }\end{array}$ & $\begin{array}{l}\text { 24-h urine free cortisol } \\
\text { (mcg/day })\end{array}$ & $\begin{array}{c}\text { Metyrapone dose oral } \\
\text { every } 6 \mathrm{~h}\end{array}$ & Etomidate & $\begin{array}{c}\text { АСТH } \\
(\mathrm{pg} / \mathrm{ml})\end{array}$ \\
\hline 0 & & 145.6 & 14766 & & & \\
\hline 10 & & 114.5 & & & Started & 1173 \\
\hline 11 & & 39.2 & 820 & & & \\
\hline 15 & I & 32.4 & & $750 \mathrm{mg}$ & & \\
\hline 17 & & 24.5 & & $1250 \mathrm{mg}$ & Stopped & \\
\hline 21 & & 22.2 & & $1250 \mathrm{mg}$ & & 243 \\
\hline 22 & & 56 & 688 & $750 \mathrm{mg}$ & & \\
\hline 37 & & 14.7 & & $1000 \mathrm{mg}$ & & \\
\hline 39 & II & & & $1000 \mathrm{mg}$ & & \\
\hline 57 & & 15.7 & & $1000 \mathrm{mg}$ & & 105 \\
\hline 60 & III & & & $1000 \mathrm{mg}$ & & \\
\hline 78 & & 16.6 & & $1000 \mathrm{mg}$ & & 157 \\
\hline 81 & IV & & & $1000 \mathrm{mg}$ & & \\
\hline 101 & V & 9.7 & & $250 \mathrm{mg}$ & & 32 \\
\hline 122 & VI & 12.9 & & $250 \mathrm{mg}$ & & 15 \\
\hline 172 & VII & & & $250 \mathrm{mg}$ & & \\
\hline 179 & & 10 & & $250 \mathrm{mg}$ & & 17 \\
\hline 193 & VIII & & & $250 \mathrm{mg}$ & & \\
\hline 211 & & 7.6 & & $250 \mathrm{mg}$ & & 58 \\
\hline 213 & & & 16.94 & $250 \mathrm{mg}$ & & \\
\hline 224 & IX & & & $250 \mathrm{mg}$ & & \\
\hline
\end{tabular}


with PRES characterized by hypertensive encephalopathy. PRES is associated with radiologic findings of symmetrical, bilateral grey and white matter abnormalities in the posterior cerebrum typically involving the temporal, parietal and occipital regions. The symptoms include headaches, decreased alertness, confusion, speech or vision abnormalities, seizures and vomiting. PRES has been associated with hypertensive encephalopathy, eclampsia, immunosuppressive therapy, systemic lupus erythromatosis, Henoch-Schonlein purpura, transplant patients and HIV (8) (9) (10).

PRES associated with Cushing's syndrome has been previously reported in children. Two were related to high dose methylprednisolone and one was from micronodular adrenocortical disease that was treated with hydrochlorothiazide and propranolol (11) (12) (13). To our knowledge, this is the first case of adult PRES associated with hypertension from ectopic ACTH causing Cushing's syndrome. Timely diagnosis and prompt intervention for PRES with blood pressure reduction is needed to avoid permanent brain damage. Hypercortisolism-induced hypertension is related to cortisol effects on vasculature, as well as mineralocorticoid, excess (14). Despite having overall weak mineralocorticoid action, cortisol is usually inactivated by the kidneys through the 11- $\beta$-hydroxysteroid dehydrogenase by converting cortisol to inactive cortisone, which protects renal mineralocorticoid receptors from minimizing its hypertensive effects (15). However, with hypercortisolism, the renal deactivation system is overwhelmed causing hypertension. Psychosis most likely resulted from hypercortisolism and uncontrolled hypertension leading to PRES. Our dilemma was that mifepristone, which blocks cortisol action, could not be escalated due to liver dysfunction, and antihypertensives including lisinopril, aldactone and metoprolol were not controlling the blood pressure (Fig. 3).

A strategy of cortisol reduction and mitigation of hypertension caused by excess cortisol production was needed (16) (17) (18). Initiation of i.v. etomidate in the intensive care unit followed by a transition to oral metyrapone to block 11- $\beta$-hydroxylation of deoxycortisol to produce cortisol and simultaneous oral spironolactone use to antagonize the mineralocorticoid action of deoxycortisol and cortisol successfully controlled her hypertension and prevented recurrence of her psychosis (Fig. 4). To the best of our knowledge, this is also the first case of a successful treatment of PRES associated with Cushing's using etomidate followed by metyrapone transition with oral spironolactone (Table 1).
Though our patient subsequently died, our intervention of treating her psychosis facilitated re-initiation of chemotherapy and extended her life for nine more months. We would like to acknowledge the team efforts by the ICU nurses and physicians, pharmacy, haematologist-oncologists, neurologists, psychiatrists, hospital medicine team and social workers at Lehigh valley Hospital Muhlenberg.

\section{Declaration of interest}

The authors declare that there is no conflict of interest that could be perceived as prejudicing the impartiality of the research reported.

\section{Funding}

This research did not receive any specific grant from any funding agency in the public, commercial or not-for-profit sector.

\section{Patient consent}

The consent form has not been obtained because the patient is deceased.

\section{Author contribution statement}

All co-authors listed contributed substantially to the preparation of this manuscript.

\section{References}

1 Ilias I, Torpy DJ, Pacak K, Mullen N, Wesley RA \& Nieman LK 2005 Cushing's syndrome due to ectopic corticotropin secretion: twenty years' experience at the National Institutes of Health. Journal of Clinical Endocrinology and Metabolism 90 4955-4962. (doi:10.1210/ jc. 2004-2527)

2 Lissoni P, Brivio F, Fumagalli L, Messina G, Secreto G, Romelli B, Fumagalli G, Rovelli F, Colciago M \& Brera G 2007 Immune and endocrine mechanisms of advanced cancer-related hypercortisolemia. In Vivo 21 647-650.

3 Pelte MF, Schwaller J \& Cerrato C 2004 Meier CA.Pro-opiomelanocortin expression in a metastatic breast carcinoma with ectopic ACTH secretion. Breast Journal 10 350-354. (doi:10.1111/j.1075-122X.2004. 21467.x)

4 Becker M \& Aron DC 1994 Ectopic ACTH syndrome and CRH-mediated Cushing's syndrome. Endocrinology and Metabolism Clinics of North America 23 585-606.

5 Wigg SJ, Ehrlich AR \& Fuller PJ 1999 Cushing's syndrome secondary to ectopic ACTH secretion from metastatic breast carcinoma. Clinical Endocrinology 50 675-678. (doi:10.1046/j.1365-2265.1999. 00726.x)

6 Uchida N, Ishiguro K, Suda T, Horie Y \& Nishimura M 2010 ACTH-producing breast cancer: a patient report. Yonago Acta Medica 53 71-75.

7 Kenchaiah M \& Hyer S 2012 Cushing's Syndrome due to Ectopic ACTH from bronchial carcinoid: a case report and review. Case Reports in Endocrinology 2012. Article ID 215038, 4 pages. (doi:10.1155/2012/ 215038) 
8 Arzanian MT, Shamsian BS, Karimzadeh P, Kajiyazdi M, Malek F \& Hammoud M 2014 Posterior reversible encephalopathy syndrome in pediatric hematologic-oncologic disease: literature review and case presentation. Iranian Journal of Child Neurology 8 1-10.

9 Hinchey J, Chaves C, Appignani B, Breen J, Pao L, Wang A, Pessin MS, Lamy C, Mas JL \& Caplan LR 1996 A reversible posterior leukoencephalopathy syndrome. New England Journal of Medicine 334 494-500. (doi:10.1056/NEJM199602223340803)

10 Casey SO, Sampaio RC, Michel E \& Truwit CL 2000 Posterior reversible encephalopathy syndrome: utility of fluid-attenuated inversion recovery MR imaging in the detection of cortical and subcortical lesions. AJNR. American Journal of Neuroradiology 21 1199-1206.

11 Lodish M, Patronas NJ \& Stratakis CA 2010 Reversible posterior encephalopathy syndrome associated with micronodular adrenocortical disease and Cushing syndrome. European Journal of Pediatrics 169 125-126. (doi:10.1007/s00431-009-0990-4)

12 İncecik F, Hergüner MÖ, Yıldızdaş D, Yılmaz M, Mert G, Horoz ÖO \& Altunbaşak Ş 2013 Posterior reversible encephalopathy syndrome due to pulse methylprednisolone therapy in a child. Turkish Journal of Pediatrics $\mathbf{5 5} 455-457$.
13 Kumar S \& Rajam L 2011 Posterior reversible encephalopathy syndrome (PRES/RPLS) during pulse steroid therapy in macrophage activation syndrome. Indian Journal of Pediatrics 78 1002-1004. (doi:10.1007/ s12098-011-0368-2)

14 Vaughan CJ \& Delanty N 2000 Hypertensive emergencies. Lancet 356 411-417. (doi:10.1016/S0140-6736(00)02539-3)

15 Walker BR, Stewart PM, Shackleton CH, Padfield PL \& Edwards CR 1993 Deficient inactivation of cortisol by 11- $\beta$-hydroxysteroid dehydrogenase in essential hypertension. Clinical Endocrinology 39 221-227. (doi:10.1111/j.1365-2265.1993.tb01778.x)

16 Drake WM, Perry LA, Hinds CJ, Lowe DG, Reznek RH \& Besser GM 1998 Emergency and prolonged use of intravenous etomidate to control hypercortisolemia in a patient with Cushing's syndrome and peritonitis. Journal of Clinical Endocrinology and Metabolism 83 3542-3544.

17 Preda VA, Sen J, Karavitaki N \& Grossman AB 2012 Etomidate in the management of hypercortisolaemia in Cushing's syndrome: a review. European Journal of Endocrinology 167 137-143. (doi:10.1530/ EJE-12-0746)

18 Feelders RA, Hofland LJ \& de Herder WW 2010 Medical treatment of Cushing's syndrome: adrenal-blocking drugs and ketaconazole. Neuroendocrinology 92 (Suppl 1) 111-115. (doi:10.1159/000314292)

Received in final form 10 August 2015

Accepted 2 September 2015 